\title{
Comparison of the Characteristics of LDPE : PP and HDPE : PP Polymer Blends
}

\author{
Sihama E. Salih ${ }^{1}$, Abdullkhaliq F. Hamood ${ }^{1}$ \& Alyaa H. Abd alsalam ${ }^{1}$ \\ ${ }^{1}$ University of Technology, Materials Engineering Department, Baghdad, Iraq \\ Correspondence: Sihama E. Salih, University of Technology, Materials Engineering Department, Baghdad, Iraq. \\ E-mail: sihama_salih@yahoo.com
}

Received: July 31, 2012

doi:10.5539/mas.v7n3p33
Accepted: January 31, $2013 \quad$ Online Published: February 22, 2013

URL: http://dx.doi.org/10.5539/mas.v7n3p33

\begin{abstract}
Comparative studies have been made on the mechanical properties of High density polyethylene/polypropylene (HDPE : PP) and Low density polyethylene/polypropylene (LDPE : PP) binary blends. Morphological analysis has been also performed using SEM. Blends have been prepared by melt mixing in an extruder. Mechanical tests were performed on the two groups of binary blends. Binary blends (HDPE : PP) gave higher values of tensile strength, fracture strength, young modulus, hardness, creep rate and creep modulus than LDPE : PP. The blend of ratio 20\%HDPE : $80 \% \mathrm{PP}$ shows superior mechanical properties, this blend could bear a load of $846.9 \mathrm{~N}$ with an extension of $3.94 \mathrm{~mm}$. SEM results indicated that 20HDPE : 80PP and 20LDPE : 80PP are immiscible blends.
\end{abstract}

Keywords: polymer blends, tensile strength, impact strength, creep rate, hardness, bending, morphology

\section{Introduction}

Plastics have become quite important and widely used materials in daily life and industry for the last forty years. One of the reasons for the great popularity of plastics in a wide variety of industrial applications is due to the tremendous range of properties exhibited by plastics and their ease of processing. A new approach to the science and technology of polymer blends has emerged recently. These polymeric materials must perform under strenuous mechanical, chemical, thermal and electrical conditions imposed by the requirements of a specific application (Xavier, 2003; Smith \& Hashemi, 2006; Samsudin, Hassan, Mokhtar, \& Jamalludin, 2006; Altan \& Yildirim, 2010; Altan, Yildirin, \& Uysal, 2011; Caliskan, Akinci, Yilimaz, \& Sen, 2011; Ronkay, 2011).

Blending of chemically different polymers is an important tool in industrial production for tailoring products with optimized material properties. Performance of polymer blends depends on the properties of polymeric components, as well as how they are arranged in space. One of the most basic questions in blends is whether or not the two polymers are miscible or exist as a single phase, most blends of high molecular weight polymers exist as two-phase materials. The morphology of the phases is of great importance in this manner. A variety of morphologies exist such as dispersed spheres of one polymer in another, lamellar structures, and co-continuous phases (Kukaleva, Cser, Jollands, \& Kosior, 2000).

Blends of polypropylene (PP) and polyethylene (PE) have become a subject of great economic and research interest because of the need to improve the processing and properties of PP as an engineering plastic due to its relatively low impact strength especially at low temperature and poor environmental stress cracking resistance. Blends of PP with linear low density polyethylene (LLDPE), very low density polyethylene (VLDPE) and ultra low density polyethylene (ULDPE) have been reported to be miscible, partially miscible or immiscible (Li, Shanks, \& Long, 2001, 2003; Utracki, 2003).

Studies from other groups showed that incompatibly immiscible polymer blends provide synergy of mechanical properties when the processing and compositional parameters are near optimum values (Petronyuk, Priadilova, Levin, Ledneva, \& Popov, 2003; Dhoble, Kulshreshtha, Ramaswami, \& Zumbrunnen, 2005; Chen, Zhon, Cai, Su, \& Yang, 2007; Wantinee, Richard, \& Jayant, 2007).

Gui et al. (2007) studied the comparison between two types of polypropylene (PP) with different molecular structure, namely, homogeneous PP (PPH) and PP block - copolymer (PPC) blended with LDPE and found these mechanical properties of the LDPE/PPH blend were much higher than that of the LDPE/PPC blend, which was attributable mainly to the fact that the mechanical properties of neat PPH are stronger than that of neat PPC. 
Also Dikabe and Luyt (2010) studied the morphologies as well as mechanical and thermal properties of two types of blends, polypropylene / linear low density polyethylene and maleic anhydride grafted polypropylene MAPP : LLDPE, PP/LLDPE blend. They showed better properties and more thermally stable than the (PP/LLDPE) as a result of the stronger interaction between MAPP and LLDPE as compare with PP and LLDPE. The aims of the present research are preparation binary polymer blends represented by (HDPE : PP) and (LDPE : PP) with different weight ratios and Studying the comparison in mechanical properties between two groups of polymer blends and also study the morphological blends by using SEM.

\section{Material and Experimental Procedure}

In this research three widely used polymer materials were used which provided from the National Company for Plastic and Chemical Industries. The polymer materials are High density polyethylene, low density polyethylene and polypropylene. Supplier and selected physical properties data for each polymer is given in Table 1. All polymers were supplied from the supplier in a pellet form.

Table 1. Polymer materials information

\begin{tabular}{cccc}
\hline polymer & supplier & Melt flow index $(\mathrm{gm} / 10 \mathrm{~min})$ & Density $\left(\mathrm{g} / \mathrm{cm}^{2}\right)$ \\
\hline HDPE & sabic & 8 & 0.964 \\
LDPE & sabic & 7 & 0.922 \\
PP & sabic & 8 & 0.905 \\
\hline
\end{tabular}

\section{Blending}

HDPE : PP and LDPE : PP blend were mixed according to the ratios displayed in Table 2 and subsequent melt processed in single screw extruder machine (Iraqi Al-Forat Company 2004 Extruder) to form long strips of polymer blends (almost $1.5 \mathrm{~mm}$ thickness) with a screw $\mathrm{L} / \mathrm{D}$ of 30:1 and the extrusion speed was (20 rpm) with barrel temperature of $(150,160 \text { and } 160)^{\circ} \mathrm{C}$ for HDPE : PP and $(140,150,150){ }^{\circ} \mathrm{C}$ for LDPE : PP from the feeding to die zone respectively.

Table 2. Blends composition

\begin{tabular}{llllll}
\hline HDPE $:$ PP & $100: 0$ & $80: 20$ & $60: 40$ & $20: 80$ & $0: 100$ \\
\hline LDPE $:$ PP & $100: 0$ & $80: 20$ & $40: 60$ & $20: 80$ & $0: 100$ \\
\hline
\end{tabular}

Samples prepared by compression moulding technique including locating previous extrdate blend strips in a mold made of steel to have the suitable thickness for inspections which is previously heated at $160{ }^{\circ} \mathrm{C}$ for one hour, compression technique carried out at pressure $\left(300 \mathrm{kgf} / \mathrm{cm}^{2}\right)$ for $(5-10)$ minutes depending on the type of the blend.

\section{Mechanical Tests}

Samples were prepared for the tensile test in accordance with ASTM D638-87 procedure, computerized universal testing machine model (WDW-50E). Jinan Shijin Group Company. The test was conducted at a constant strain rate of the order $10 \mathrm{~mm} / \mathrm{min}$ at room temperature. Tensile stress was applied till the failure of the sample and stress strain curve was obtained .Each sample was tested for 3 times and average results have been reported.

Impact test is performed at room temperature according to ASTM ISO 179, Izod charpy tension impact test measurement test machines, XJU-22 Time group Inc.

Bending elasticity modulus measured from three point test, this test is performed according to ASTM D790-78 at room temperature.

Hardness test carried out on a durometer D scale (ASTM D570) with specimen dimension $(10 \times 10 \times 4) \mathrm{mm}$. Creep tests are performed under a constant applied load $(40 \mathrm{~N})$ at room temperature according to (ASTM BS 1178). 


\section{Results and Discussion}

\subsection{Tensile Test}

The results of tensile tests (stress-strain curves) for the blends of HDPE : PP and LDPE : PP were presented in the following Figures 1 and 2 respectively. The results show pure polypropylene has higher mechanical properties than the both types of polymer blends components and that related to PP have a rigid shortly methyl group attached to every second carbon atom of the polymer main chain, which restricts rotation of the chain producing a stronger but less flexible material (Smith \& Hashemi, 2006), whereas HDPE and LDPE show elastic behavior (soft and weak), so they have lower tensile strength and higher elongation as compared to pure PP, from the other hand these figures show the behavior of both types of blends which are intermediate between their pure polymers. By increasing of weight percentages of PP from $20 \%$ to $80 \%$ there will be change in the behavior from soft and tough with low percentage of PP to hard and tough with high percentage of PP in the blend. It can also be noted that the blends of ratio $20 \% \mathrm{HDPE}: 80 \% \mathrm{PP}$ and $20 \% \mathrm{LDPE}: 80 \% \mathrm{PP}$ can withstand maximum load at a particular applied load as compared to samples of other ratios. These blends could bear a load of $846.9 \mathrm{~N}$ and $726.8 \mathrm{~N}$ with an extension of $3.94 \mathrm{~mm}$ and $4.07 \mathrm{~mm}$ respectively.

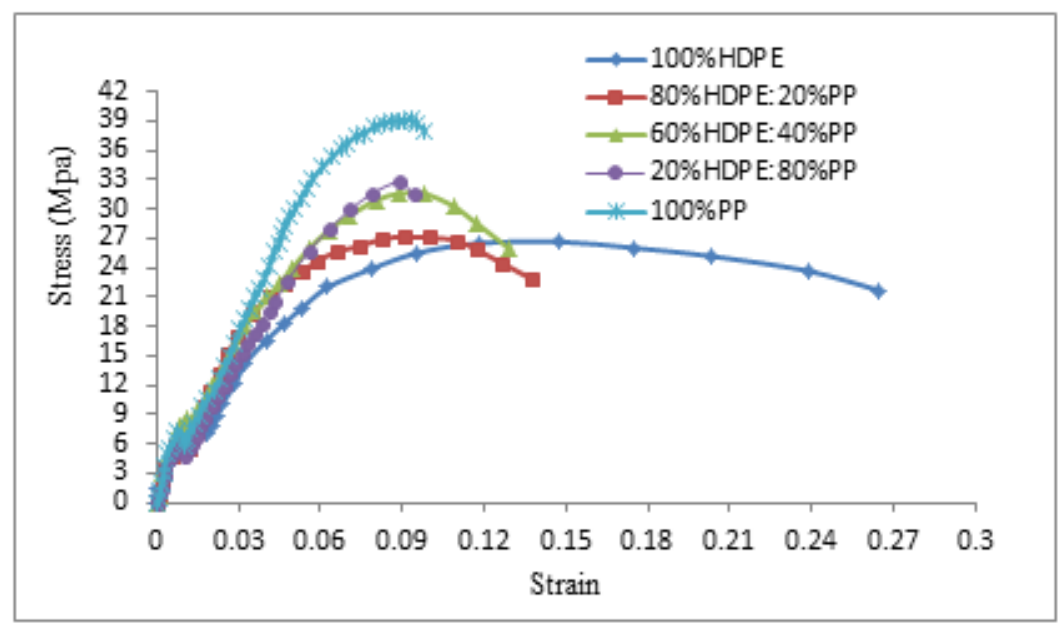

Figure 1. Stress-strain curve of HDPE : PP polymer blends

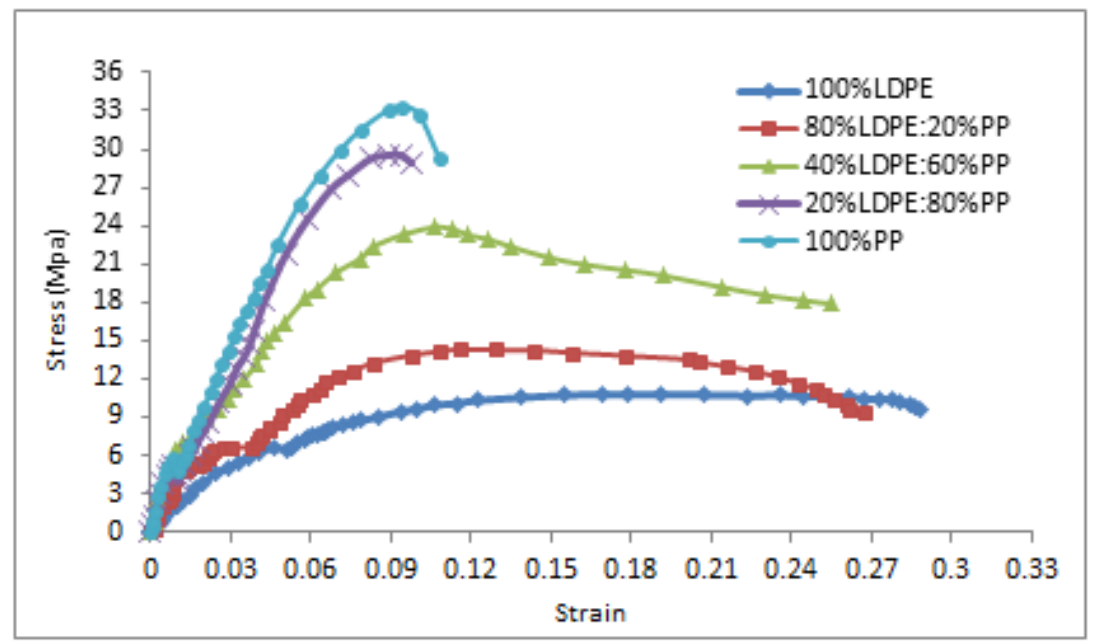

Figure 2. Stress-strain curve of LDPE : PP polymer blends

The mechanical properties for both groups of blends (Ultimate tensile strength, Fracture strength, Young modulus and elongation) presented as a function of PP content in Figures $3 \mathrm{a}, \mathrm{b}, \mathrm{c}$ and $\mathrm{d}$ respectively which indicate to the increasing of all the mechanical properties with increasing PP content except elongation property which decreased with the increment of PP due to the fact that PP is strong as compared with HDPE and LDPE. 

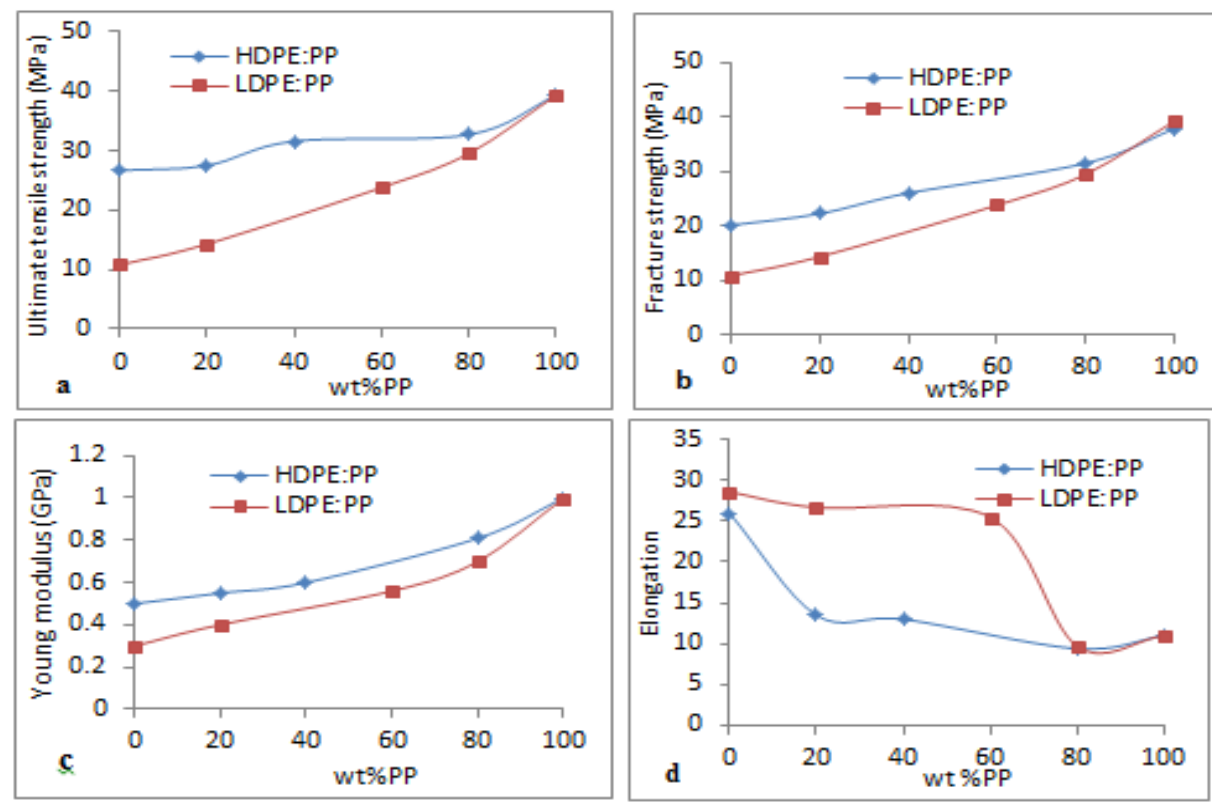

Figure 3. Mechanical Properties of (a) Ultimate tensile strength, (b) Fracture strength (c) Young modulus and (d) Elongation of HDPE : PP and LDPE : PP polymer blends

\subsection{Impact Test Results}

The Impact toughness is often the deciding factor in material selection because impact test measures the ability of polymer to withstand the load imposed upon being struck by an object at high velocity, thus it is a measure of energy required to propagate a crack cross the specimen, therefore the impact properties of these samples are especially important.

From Figures 4 and 5 which were shown the effect of blend ratio on impact strength and fracture toughness respectively for (HDPE : PP) and (LDPE : PP) polymer blends, there is symmetric behavior in both groups of blend and HDPE : PP blends have higher impact strength and fracture toughness values as compared with LDPE : PP blends due to the compatibility between PP and HDPE in some percentage as a result to their structure while this cannot applied to LDPE since the molecular chains in the LDPE are more branched and farther apart from each other, the bonding forces between the chains are lower and hence lower strength (Smith \& Hashemi, 2006; Petronyuk, Priadilova, Levin, Ledneva, \& Popov, 2003).

It is obvious from Figure 4 that there are a depression in impact strength these values for HDPE and LDPE when mixed with PP, and the depression ratio decreased with increase of weight percentage of PP and that belongs to a rigid shortly methyl group attached to every second carbon atom in the linear molecular chain of PP and this cause PP has relatively low impact strength (Smith \& Hashemi, 2006; Dhoble, Kulshreshtha, Ramaswami, \& Zumbrunnen, 2005).

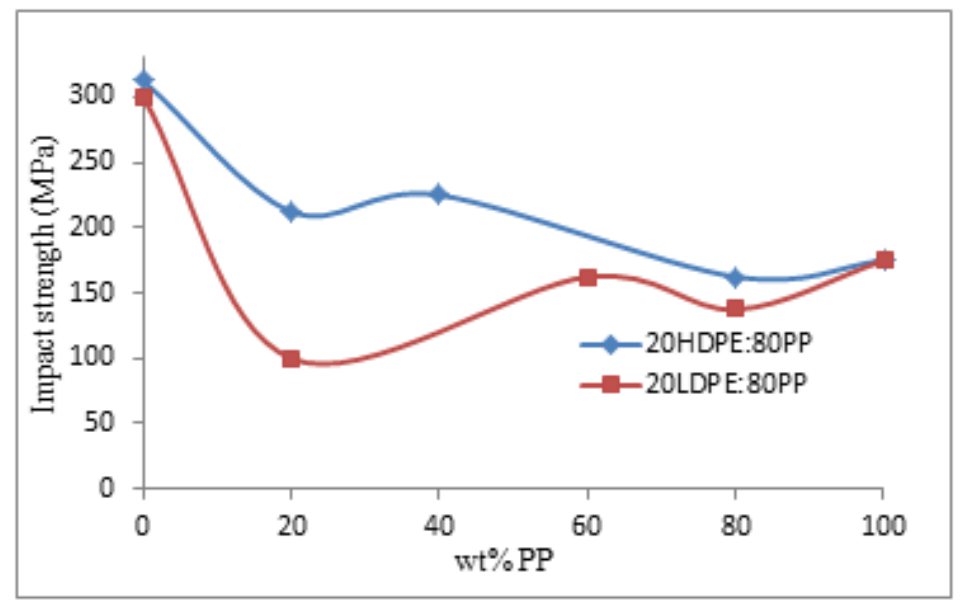

Figure 4. The effect of blend ratio on Impact Strength HDPE : PP and LDPE : PP polymer blends 


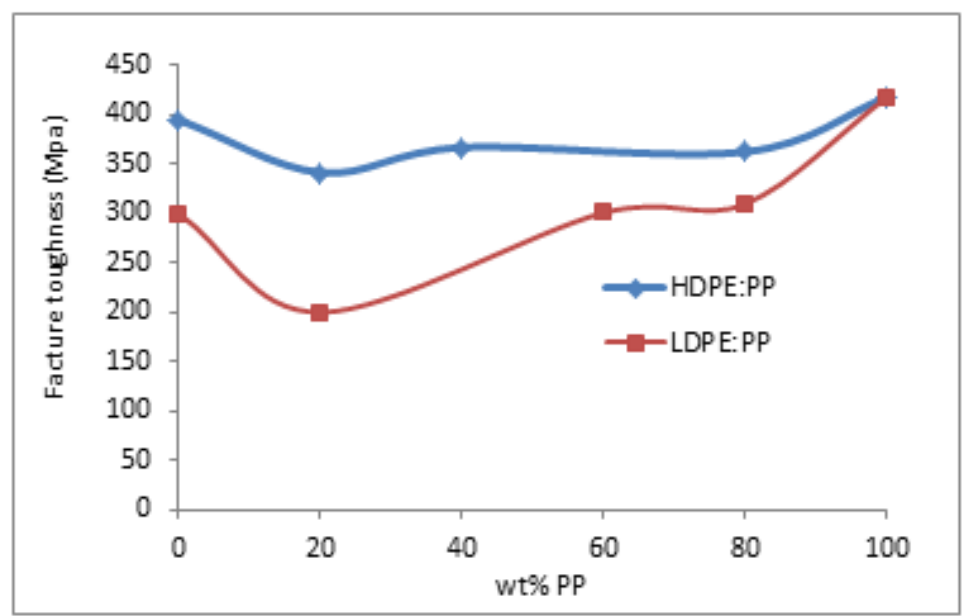

Figure 5. The effect of blend ratio on Fracture toughness of HDPE : PP and LDPE : PP polymer blends

\subsection{Bending Test Results}

It has been realized from Figure 6 which shows that bending modulus $\left(\mathrm{E}_{\text {bend. }}\right)$ of HDPE : PP and LDPE : PP blends increased as PP weight ratio increased and ( $\mathrm{E}_{\text {bend. }}$ ) for the first blend (HDPE : PP) is higher than (LDPE : PP) due to PP compatibility with HDPE is better than from LDPE as long as LDPE has a branched chain structure, HDPE in contrast has very little branching on the main chains.

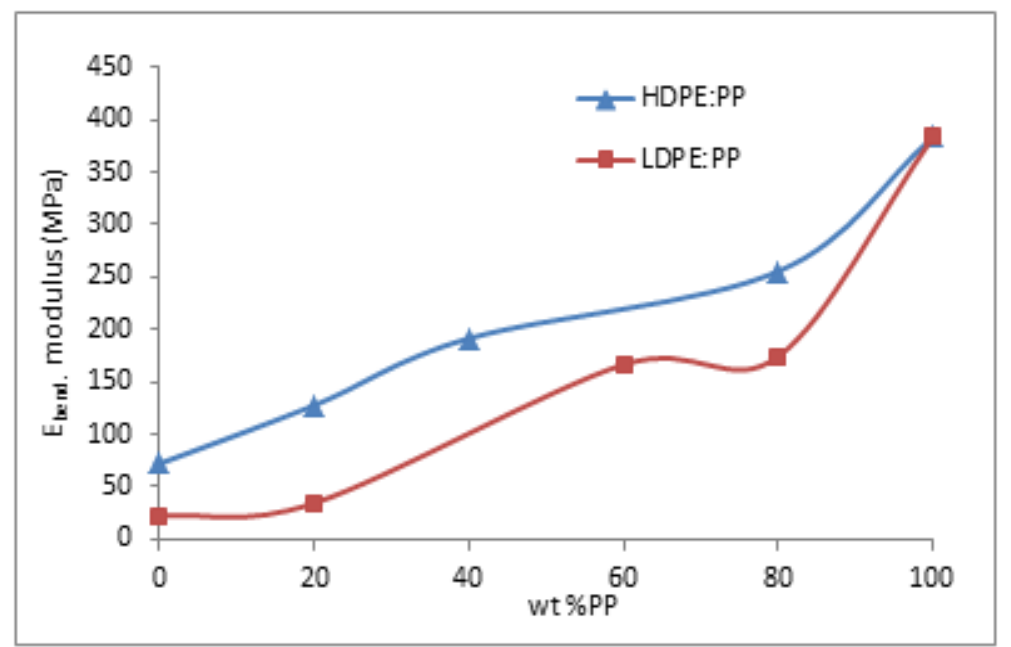

Figure 6. The effect of blend ratio on bending modulus of elasticity of HDPE : PP and LDPE : PP polymer blends

\subsection{Creep Test Results}

Whenever products made of polymeric materials are exposed to a constant load at constant temperature, their propensity to creep which considerably affects their dimensional stability with time becomes a most important characteristic. Thus, the acquisition of creep data over appropriate periods of time and their analysis are undoubtedly of great practical interest as shown in the following Figures 7 and 8 which represents creep behavior of (HDPE : PP) and (LDPE : PP) blends respectively over a period of time, it appears that PP has higher resistance to creep as compared with HDPE and LDPE or with their blends since the differences in the structure. But still the creep behavior of blends is between their plain polymers. And from Figures 9 and 10 there were good evidence that creep modulus (the ratio of the initial applied stress to the creep strain $\epsilon_{(t)}$ after a particular time and at a constant temperature of testing (Smith \& Hashemi, 2006)) increased as PP content increased for both blends (HDPE : PP) and (LDPE : PP) respectively. Also these figures show that creep modulus at the beginning slightly increase with increment of weight ratio of PP until reach to middle then the creep modulus values increase very rapidly with increased PP content of the blend, the high values for the creep modulus of the polymer blend thus implies a low creep rate as shown in Figures 7 and 8, and this related to the effect of bulky side group (a methyl group) on every 
second atom of the PP main chain restricts rotation of the chain ,producing a strong intermolecular forces but less flexible material and this reduce the creep rate (Smith \& Hashemi, 2006). And also it can be seen from Figures 9 and 10 the creep modulus decreases with the increasing of creep time.

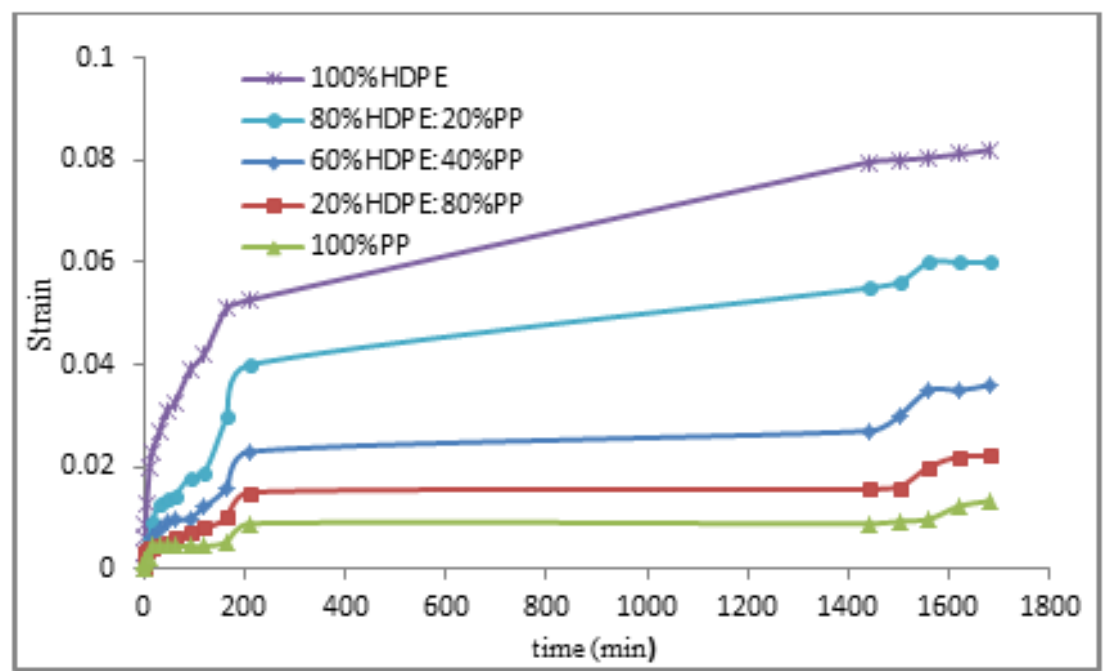

Figure 7. Creep results of plain polymers and HDPE : PP polymer blends

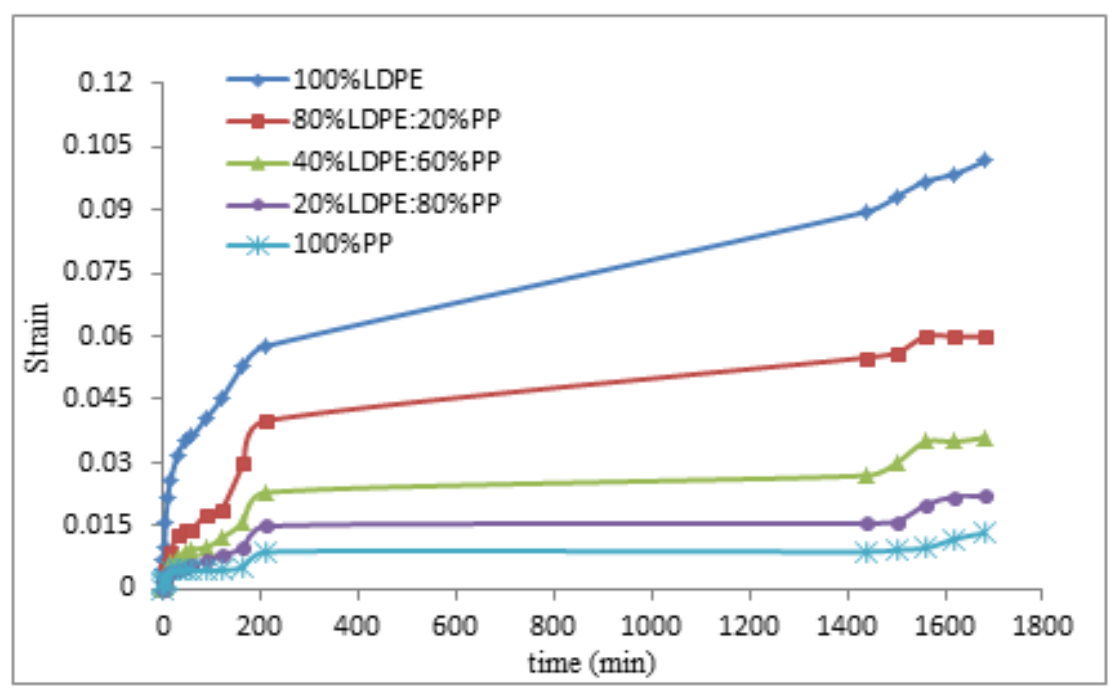

Figure 8. Creep results of plain polymers and LDPE : PP polymer blends 


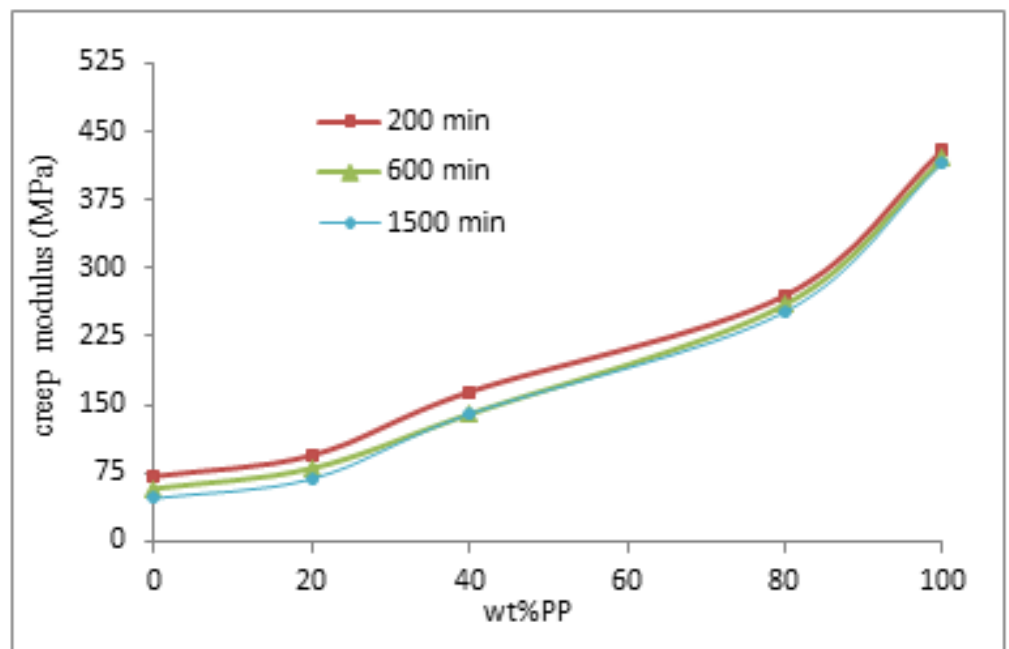

Figure 9. The effect of PP content on creep modulus of (HDPE : PP) polymer blends

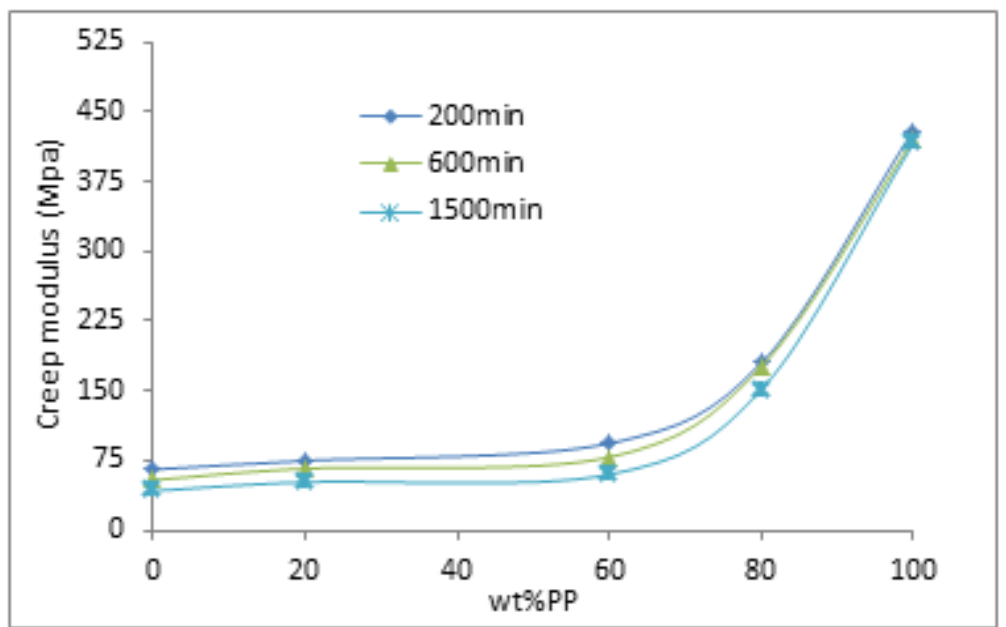

Figure 10. The effect of PP content on creep modulus of (LDPE : PP) polymer blends

\subsection{Hardness Test Results}

The variation in the Shore D hardness values of HDPE : PP and LDPE : PP is shown in Figure 11. As it has been mentioned previously that PP is stronger and more rigid than both HDPE and LDPE (Smith \& Hashemi, 2006; Shan, Yang, Xie, \& Yang, 2007). Shore D results confirmed these facts since PP has higher hardness value than the other named polymers. Furthermore it noticed that shore D values for (HDPE : PP) and (LDPE : PP) blends increased as the weight ratio of PP increased as a result to the nature of PP which is more stiff than any one of PE. The increased rate of shore D hardness for the first blend (HDPE : PP) was higher than the second one this belong to the difference between both types of PE in molecular chain structure. From these two curves it has been noticed that the highest value have been recorded at $20: 80$ (HDPE : PP) blend which were 77. 


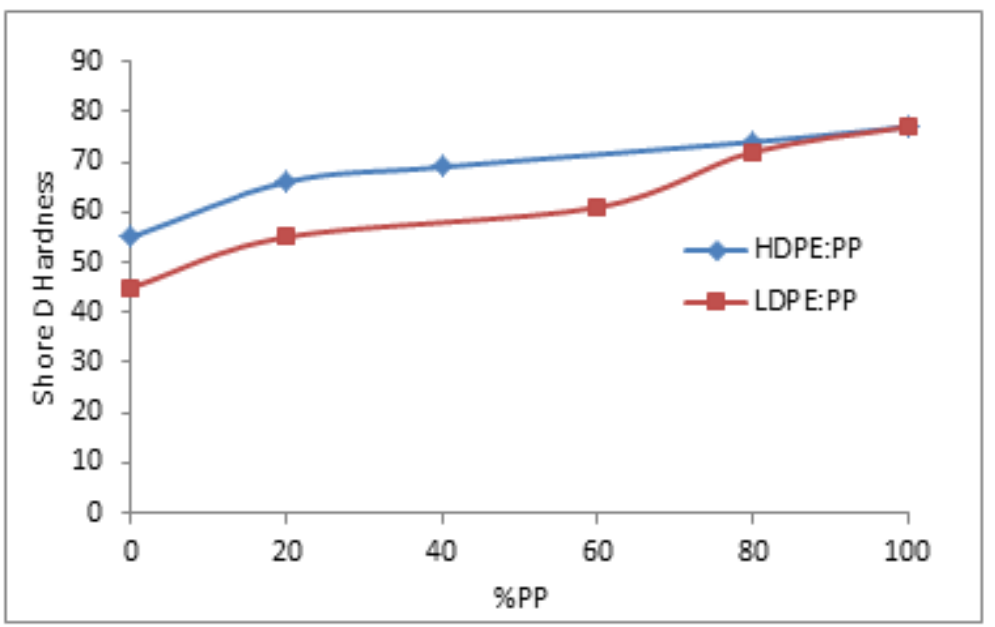

Figure 11. Shore D Hardness of (HDPE : PP and LDPE : PP) polymer blends

\subsection{Morphology Results}

In order to evaluate the changes in surface morphology of the polymer blends, polymer blends 20HDPE : 80PP and 20LDPE : 80PP were subjected to scanning electron microscopic (SEM). To achieve good electric conductivity, these samples were first carbon sputtered and then line of silver has been made from the surface along the edge of the sample before examination.

The morphology of immiscible polymer blends depends on the component, ratios, component melt viscosities and processing conditions. In most heterogeneous system morphology where by one phase is distributed in another phase is observed (Dikobe \& Tyyt, 2010).

SEM micrographs clearly show the difference in the morphology of the polymer blends (20HDPE : 80PP) and (20LDPE : 80PP) Figure $12 \mathrm{a}$ and $\mathrm{b}$. From these figures HDPE : PP and LDPE : PP blends are completely incompatible, there is some phases are grossly separated, however, that interfacial adhesion between domains and continuous phases are observed for the first blend 20HDPE : 80PP where such adhesion is not clearly observed for the LDPE : PP blend of the same composition.

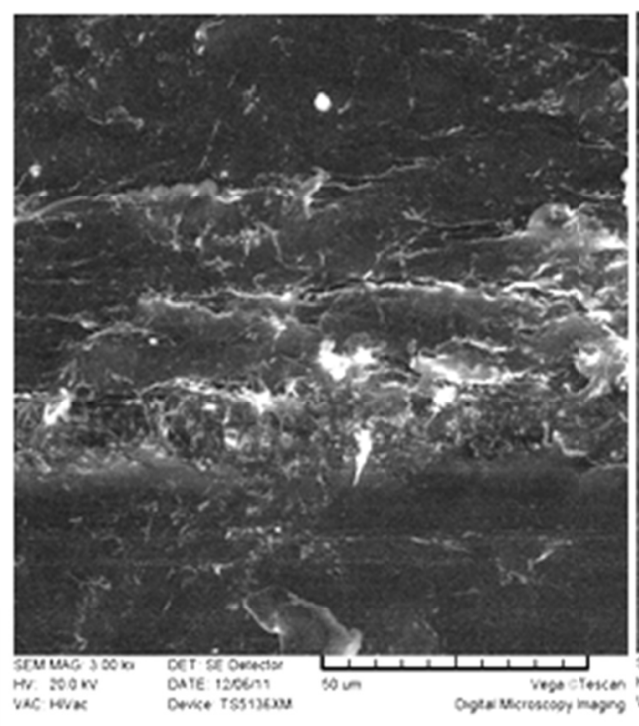

(a) 20HDPE:SOPP

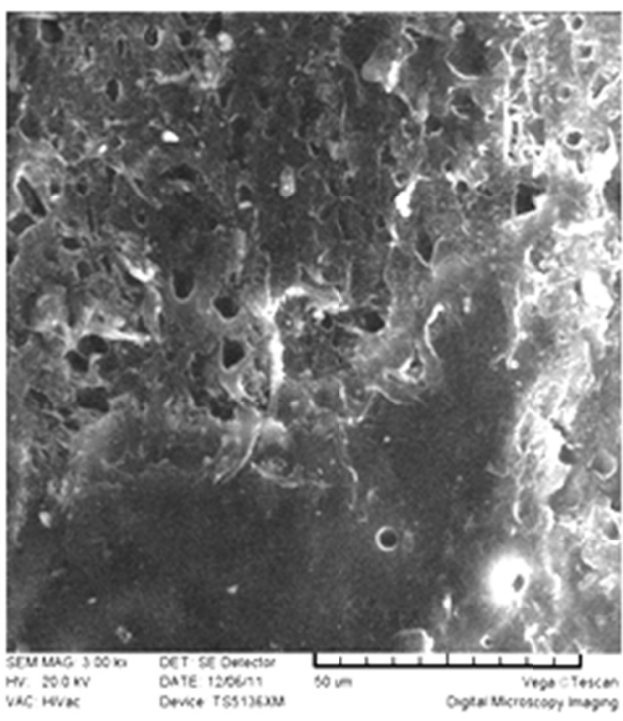

(b)20LDPE:SOPP

Figure 12. SEM micrographs of (20HDPE : 80PP and 20LDPE : 80PP) polymer blend 


\section{Conclusion}

The present study has investigated the effect of the blend ratio on the mechanical properties of HDPE : PP and LDPE : PP and the results were as following:

1) The mechanical properties of HDPE : PP blends gave higher values compared to LDPE : PP blends.

2) Mechanical properties such as (Tensile strength, Fracture stress, Young modulus, Bending modulus, creep modulus and hardness) of both HDPE : PP and LDPE : PP blend increased with increment of PP weight percentage except elongation which decreased. It has been noted that (20:80) of (HDPE : PP and LDPE : PP) appeared to withstand high loads as it is compared to other samples of other ratios.

3) 20HDPE : 80PP and 20LDPE : 80PP blends are completely incompatible at which there is some phases are grossly separated.

\section{References}

Altan, M., \& Yildirim, H. (2010). Mechanical and Morphological Properties of Polypropylene and High Density Polyethylene Matrix Composites Reinforced with Surface Modified Nano Sized $\mathrm{TiO}_{2}$ Particles. World Academy of Science, Engineering and Technology, 70, 289-294.

Altan, M., Yildirin, H., \& Uysal, A. (2011). Tensile properties of Polypropylene /metal oxide nano composites. The online Journal of Science and Technology, 1(1), 25-29.

Caliskan, M., Akinci, A., Yilimaz, S., \& Sen, U. (2011). Assignment of Mechanical properties of Basalt-LDPE composite materials using experimental and computer aided simulation methods. Scientific Research and Essay, 6(11), 2315-2324.

Chen, J. H., Zhon, J. C., Cai, Y. H., Su, W. B., \& Yang, Y. B. (2007). Morphology and Thermal properties of the bonery blends of poly (propylene-co-ethylene) copolymer and isotactic polypropylene with polyethylene. Polymer, 48, 2946-2957. http://dx.doi.org/10.1016/j.polymer.2007.03.037

Dhoble, A., Kulshreshtha, B., Ramaswami, S., \& Zumbrunnen, D. A. (2005). Mechanical Properties of PP-LDPE Blends with Novel Morphologies Produced with a Continuous Chaotic Advection Blender. Polymer, 46, 2244-2256. http://dx.doi.org/10.1016/j.polymer.2005.01.057

Dikobe, D., \& Tyyt, A. S. (2010). Comparative study of the Morphology and Properties of PP/LLDPE/Wood powder and MAPP/LLDPE/Wood powder polymer blend composites. XPRESS Polymer Letters, 4, 729-741. http://dx.doi.org/10.3144/expresspolymlett.2010.88

Li, J., Shanks, R. A., \& Long, Y. (2001). Miscibility and Crystallisation of Polypropylene-Linear Low Density Polyethylene Blends. Polymer, 42, 1941-1951. http://dx.doi.org/10.1016/S0032-3861(00)00484-5

Li, J., Shanks, R. A., \& Long, Y. (2003). Miscibility and Crystallization of Metallocene Polyethylene Blends with Polypropylene. J. Appl. Polym. Sci., 87, 1179-1189. http://dx.doi.org/10.1002/app.11412

Kukaleva, N., Cser, F., Jollands, M., \& Kosior, E. (2000). Comparison of Structure and Properties of Conventional and "High-Crystallinity" Isotactic Polypropylenes and their Blends with MetalloceneCatalyzed Linear Low-Density Polyethylene. I. Relationships between Rheological Behavior and Thermal and Physical Properties. J. Appl. Polym. Sci., 77, 1591-1599. http://dx.doi.org/10.1002/1097-4628(20000815)77:7<1591::AID-APP20>3.0.CO;2-M

Petronyuk, J. S., Priadilova, O. V., Levin, V. M., Ledneva, O. A., \& Popov, A. A. (2003). Structure and elastic properties of immiscible LDPE-PP blends: dependence on composition. Mat. Res. Soc. Synup. Proc., 740.

Ronkay, F. (2011). Impact of fiber reinforcement on polymer blend properties. Society of Plastics Engineers.

Samsudin, S. A., Hassan, A., Mokhtar, M., \& Jamalludin, S. M. (2006). Chemical Resistance Evaluation of polystyrene/polypropylene blend: Effect of blend composition and SEBS content. Malaysian Polymer Journal (MPJ), 1(1), 11-24.

Shan, G. F., Yang, W., Xie, B. H., \& Yang, M. B. (2007). Mechanical Properties and Morphology of LDPE/PP Blends. Journal of Macromolecular Science Part B: Physics, 46(5), 963-974. http://dx.doi.org/10.1080/00222340701457253

Smith, W. F., \& Hashemi, J. (2006). Foundations of Material Science and Engineering (4th ed.). New York, Magraw Hill.

Utracki, L. A. (2003). Thermodynamics of Polymer Blends. Polymer Blends Handbook, 123-201. Kluwer Academic Publishers. http://dx.doi.org/10.1016/S0032-3861(00)00484-5 
Wantinee, V., Richard, L. L., \& Jayant, J. (2007). Impact resistance of selected immiscible polymer blends. Society of Plastics Engineers Annual Technical Conference Proceedings Cincinnati, May.

Xavier, S. F. (2003). Properties and Performance of Polymer Blends. Polymer Blends Handbook, 861-950. Kluwer Academic Publishers. http://dx.doi.org/10.1007/0-306-48244-4_12 